\title{
Descripción del estado de salud de indígenas Huitoto y Embera de Florencia, Caquetá a través de pruebas de laboratorio, en el primer período de 2012
}

\author{
Description of the health status of indigenous Huitoto and Embera of \\ Florencia Caquetá trough laboratory tests in the first period of 2012 \\ Martha Castillo Bohórquez¹, Ana Isabel Mora Bautista1', Ana Lucia Oliveros Rozo', Leidy Milena Jiménez \\ Tobo², Luz Myriam Parrales Solarte², Nancy Carolina Suárez Católico².
}

\begin{abstract}
Resumen
Objetivo. Describir la presencia de anemia, infecciones y parasitismo intestinal en comunidades indígenas colombianas Huitoto y Embera residentes en Florencia, Caquetá a partir de pruebas de laboratorio como: cuadro hemático, frotis de sangre periférica (FSP), ferritina, proteína $\mathrm{C}$ reactiva (PCR), parcial de orina y coprológico. Materiales y métodos. Se recolectaron muestras de sangre, orina y materia fecal, de adultos entre los 18 y 79 años. Resultados. Se encontró que las dos comunidades indígenas presentaban deficiencias en el estado de salud representadas por alto nivel de parasitismo intestinal, presencia de anemia en algunos de los individuos, al igual que una baja prevalencia de infección urinaria. Se sugiere implementar campañas de promoción y prevención de la salud de estas comunidades indígenas
\end{abstract}

Palabras clave: Huitotos, Emberas, Florencia, anemia, parasitismo intestinal, infección urinaria.

\begin{abstract}
Objetive. Describe the presence of anemia, infections and intestinal parasitism in Colombian indigenous communities Huitoto and Embera residents in Florencia, Caquetá. Materials and Methods: Laboratory test such as: hemogram, peripheral blood smear (FSP), Ferritin, C-reactive protein (CRP), partial of urine and stool. In the study were collected blood samples, urine and stool, of adults between 18 and 79 years. Results. It was found that the two communities had deficiencies in health status represented by high level of intestinal parasitism, anemia in some individuals, as well as a low prevalence of urinary tract infection. In response to the problems described above, the group of research suggests deploy campaigns of health promotion and disease prevention related to the findings on the health status of these indigenous communities.
\end{abstract}

Key Words: Huitotos, Emberas, Florencia, anemia, intestinal parasitism, urinary tract infection.

1. Docentes investigadoras semillero ERITRON Universidad Colegio Mayor de Cundinamarca.

2. Estudiantes del programa de Bacteriología y Laboratorio Clínico de la Universidad Colegio Mayor de Cundinamarca.

Correspondencia: mlcastillo@unicolmayor.edu.co

Recibido: 10/10/2014 Aceptado: 10/06/2015 


\section{Introducción}

Las comunidades indígenas distribuidas en el ámbito mundial son un grupo de personas con diferentes costumbres y tradiciones propias según el país al que pertenecen. Se ha observado que a estas etnias se les tiene como un grupo marginado en cada país, ya que están dispuestos a continuar sus tradiciones y poseen sistemas sociales, económicos o políticos distintos a los de las "civilizaciones".

La Organización mundial de la salud, OMS, designa a la discriminación como uno de los principales factores que altera el derecho a gozar de un servicio de salud con calidad, y potencia a la vez la situación de pobreza. Esta problemática se presenta con frecuencia en minorías étnicas, religiosas, lingüísticas, incluyendo las comunidades indígenas y marginadas por la sociedad (1). Sin embargo no hay que dejar de lado que las comunidades indígenas, en cada uno de sus países están protegidas por entes gubernamentales, en el caso de Colombia, la Constitución política de 1991, en varios de sus artículos resalta que "El Estado reconoce y protege la diversidad étnica y cultural de la nación colombiana” (2). Estos grupos, intentan cuidar el medio donde se desarrollan, porque son conscientes del patrimonio natural con el que cuentan. Esto es respaldado por entidades como el Fondo Internacional de Desarrollo Agrícola, quien en su escrito denominado: "Los pueblos indígenas: valorar, respetar y apoyar la diversidad", destaca la importancia de estas comunidades valiosas para la población mundial (3).

En América Latina existen países que contienen gran cantidad de grupos indígenas en su territorio, a los cuales se les tiene abandonados en cuanto a cubrimiento en salud, pese a los programas que existen en pro de mejorar el problema. La importancia de brindar servicios de salud a estos pueblos, radica en reconocer que son grupos nativos que forman parte del patrimonio cultural de las naciones y que actualmente enfrentan problemas como desnutrición y elevadas tasas de morbimortalidad, consecuencia del conflicto armado y el acceso inoportuno a los servicios de salud, que podrían contribuir con su desaparición.

La medicina tradicional es la herramienta que los indígenas utilizan para mejorar la condición de enfermedad, lo que sugiere problemas en cuanto al diagnóstico y a la implementación de tratamientos oportunos contra los diversos padecimientos.

En Colombia existen algunos estudios que evidencian la frecuencia de enfermedades que se presentan en las diferentes comunidades indígenas, por tal motivo, se ve la necesidad de realizar un estudio del estado de salud de estas personas que viven en condiciones sanitarias poco óptimas y que están alejadas de los centros urbanos donde se concentran los servicios sanitarios.

Es importante conocer cuál es el estado de salud de las comunidades indígenas Huitotos y Emberas, descrito a través de pruebas de laboratorio convencionales, y de esta manera generar intervención por parte de entidades gubernamentales propias de estos grupos y del Estado que contribuya al mejoramiento de calidad de vida de esta población y que se pueda generar programas de atención primaria para disminuir las deficiencias nutricionales y el poliparasitismo que diariamente incrementan la tasa de morbimortalidad de estas comunidades.

De acuerdo a lo descrito por el "Informe epidemiológico Nacional del 2009” existen altas tasas de mortalidad y morbilidad en las comunidades indígenas del país, lo que se empeora más con la escasa cobertura en salud, y la migración de estas comunidades lejos de sus áreas geográficas nativas (4).

Según el estudio realizado por la universidad Javeriana denominado "Estado de salud infantil en las comunidades indígenas, afrocolombianas y aisladas en Colombia”, las enfermedades más comunes diagnosticadas durante el trabajo de campo fueron, el parasitismo intestinal, seguido de la infección respiratoria aguda, caries dentales, enfermedad diarreica y desnutrición. En consecuencia 
ellos postulan la necesidad de realizar más estudios que permitan establecer las condiciones de salud de estas comunidades (5). Por lo anterior se constituye importante el presente trabajo, para tener continuidad con este tipo de investigaciones, que involucran los grupos indígenas, patrimonio cultural de la nación. De esta manera, en la investigación se plantea como principal objetivo, describir la presencia de anemia, infección urinaria y parasitismo intestinal en Comunidades indígenas colombianas: Huitotos y Emberas residentes en la ciudad de Florencia a partir de pruebas de laboratorio.

\section{Materiales y métodos}

La muestra del estudio correspondió a los hombres y mujeres que cumplieran los siguientes criterios de inclusión: ser mayor de 18 ańos, pertenecer a las comunidades indígenas Huitoto y Embera de la ciudad de Florencia Caquetá, y haber autorizado su participación en el estudio firmando el consentimiento informado.

La obtención de la información para llevar a cabo la investigación se realizó, inicialmente con una sensibilización previa a la toma de muestras, que se dirigió a los 4 cabildos indígenas de las comunidades Huitoto y Embera para dar a conocer la importancia del estudio y las condiciones que debían cumplir para la recolección de las muestras. Posteriormente, se entregó a cada individuo el consentimiento informado, para ser leído y firmado por quienes aceptaban participar y al mismo tiempo se realizó el diligenciamiento de la encuesta sociodemográfica propuesta por el grupo de investigación. La información también se recolectó a partir de los resultados de las pruebas de laboratorio, realizadas para valorar el estado de salud de las comunidades indígenas, las cuales fueron:

\section{Hemograma de tercera generación}

Se tomaron 55 muestras de sangre anticoagulada recolectada por flebotomía con anticoagulante EDTA, las cuales se procesaron en el equipo de hematología de tercera generación, Abacus Junior, del Hospital Regional de las Malvinas de la Ciudad de Florencia, Caquetá, el cual funciona por impedancia eléctrica.

\section{Frotis de sangre periférica}

Se realizaron los extendidos, de las 55 muestras tomadas para el cuadro hemático, en lámina portaobjetos con una gota de sangre, se dejó secar y se coloreó empleando la coloración de Wright. Posteriormente se evalúo por microscopía óptica la morfología y distribución de las células sanguíneas, al igual que la presencia de hemoparásitos.

\section{Uroanálisis}

Se explicó a cada una de las comunidades que la recolección de la orina debía ser en un recipiente estéril, de plástico con cierre hermético, proporcionado por el grupo de investigación. Se indicó que fuera la primera micción de la mañana, con previo aseo genital, descartando el primer chorro y recolectando el resto de La orina hasta completar el volumen deseado. Se les indicó también que llenarán la tercera parte del frasco y lo llevarán al lugar de recepción de las muestras en un tiempo no mayor de 2 horas. Se valoraron los resultados del análisis físico, químico y microscópico de 54 muestras de orina recolectadas, para determinar si había o no infección urinaria en los participantes. Se excluyeron del análisis las muestras que mostraban contaminación con flujo vaginal.

\section{Coprológico}

Se explicó a cada una de las comunidades que la recolección de la materia fecal debía ser en un recipiente estéril, de plástico con cierre hermético, proporcionado por el grupo de investigación. Se recolectaron 45 muestras en las que se evaluaron parámetros físicos, químicos y microscópicos en la búsqueda de parásitos intestinales. 


\section{Ferritina}

Se tomaron 55 muestras en tubos secos tapa roja a través de flebotomía. La muestra se centrifugó por 10 minutos a 2500 revoluciones por minuto y se evaluó la presencia y cantidad de dicha proteína en suero por "Human Ferritin Enzyme Immunoassay Test Kit", que sugiere valores de referencia para Hombres de 32.0 $\mathrm{ng} / \mathrm{ml}$ a $501.0 \mathrm{ng} / \mathrm{ml}$ y para mujeres de $3.5 \mathrm{ng} / \mathrm{ml} \mathrm{a}$ $223.5 \mathrm{ng} / \mathrm{ml}(5-6)$.

\section{Proteina C Reactiva}

Usando el suero de las 55 muestras ya centrifugadas, se valoró la presencia de esta proteína por el test rápido para la determinación cualitativa y semicuantitativa de proteína C Reactiva por aglutinación de las partículas de látex en portaobjetos, que sugiere valores normales de 0.02 hasta $13.5 \mathrm{mg} / \mathrm{l}$ (7). Es muy importante destacar que después del análisis de estas muestras, se realizó todo el proceso de inactivación y eliminación del material de riesgo biológico en el lugar de procesamiento.

Posterior a los análisis y resultados de las pruebas, se organizó la información de manera estadística con el fin de describir los hallazgos encontrados. Inicialmente todas las variables numéricas se categorizaron de acuerdo con criterios sociodemográficos y clínicos.

Se describieron todas las variables a través de proporciones mediante el programa estadístico SPSS 17.0, se construyó una tabla de $2 \mathrm{X} 2$ para establecer la relación de asociación entre la parasitosis y la presencia porcentual de eosinófilos utilizando el test de Fisher para analizar esta asociación, estableciéndose como una relación significativa cuando p es $\leq 0.05$.

Los resultados del estudio se socializaron a las comunidades indígenas participantes, a través de una charla acerca de hábitos saludables para disminuir el riesgo de padecer anemia, infecciones urinarias y parasitosis intestinal. Además se hizo entrega de una cartilla didáctica denominada: "Cuerpo sano familias felices", diseñada por el grupo de investigación.

\section{Resultados}

En el estudio participaron dos cabildos Huitoto y dos cabildos Embera, a continuación se puede observar la distribución de participantes.



Figura 1. Distribución de la población Indígena Huitoto y Embera 
En cuanto a la distribución de participantes se evidencia que la comunidad Huitoto Hetñhe Jitoma fue la que aporto más participantes al estudio con un total de 21 individuos que representan un $37 \%$.
La mayoría de los individuos de las cuatro comunidades se encuentra en un IMC normal según los valores de referencia de la OMS, sin embargo el $29.3 \%$ presentan sobrepeso y el $14.2 \%$ de las personas pertenecientes al cabildo Embera Chami País Amazonia muestran obesidad.

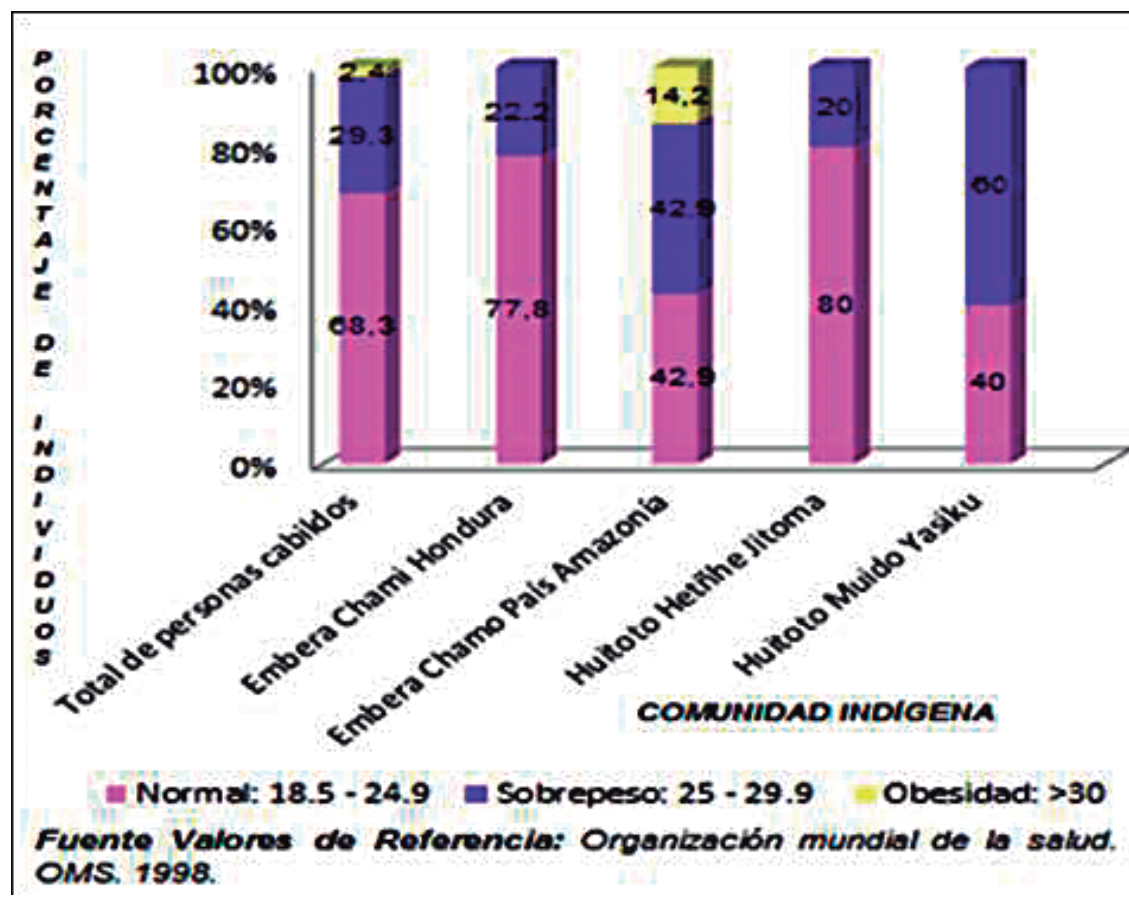

Figura 2. Determinación del índice de masa corporal de los participantes

El análisis del parcial de orina en los cuatro cabildos mostro que un gran porcentaje no presenta infección urinaria, sin embargo este hallazgo se encontró en el 4\% de la población. Figura 3.

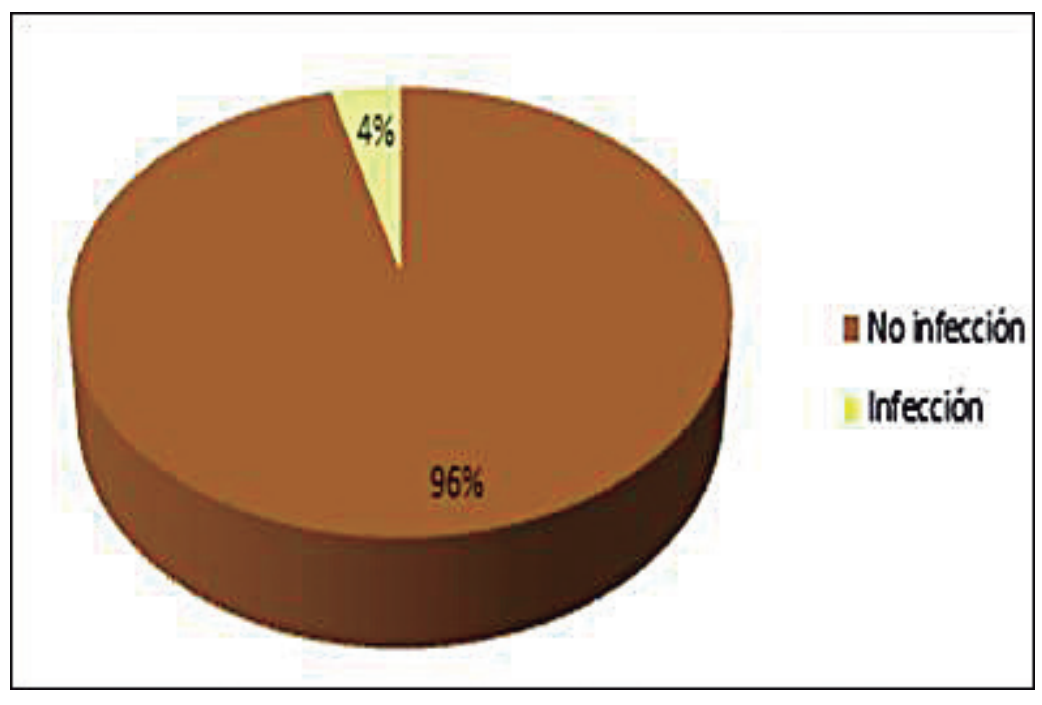

Figura 3. Hallazgos del uroanálisis en la población indígena participante 
La prevalencia de parásitos intestinales fue del $86.67 \%$ para las muestras procesadas en los cuatro cabildos indígenas participantes en el estudio. Se evidencia que en el 69,23\% de las muestras analizadas se observo la presencia de más de un parasito, considerándose esta condición como poliparasitismo.
Se observa que el parasito de mayor presencia es el Blastocystis hominis seguido de Endolimax nana, Complejo E. histolytica-E. dispar y Entamoeba coli. Figura 4.

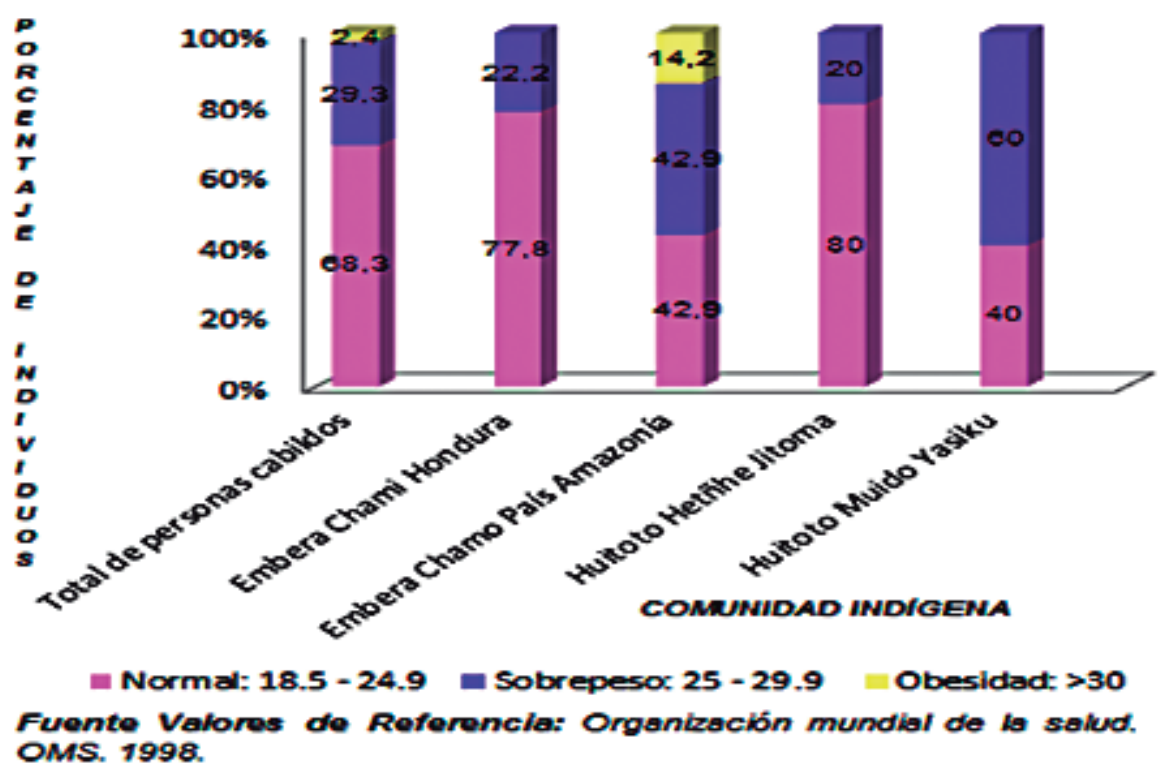

Figura 4. Descripción de parásitos intestinales presentes en la comunidad

Se observa que las mujeres presentan valores de hemoglobina más bajos que los hombres. Se observa que el 30.6\% de las mujeres presentan anemia, mientras solo el 5.3\% de los hombres la padecía.

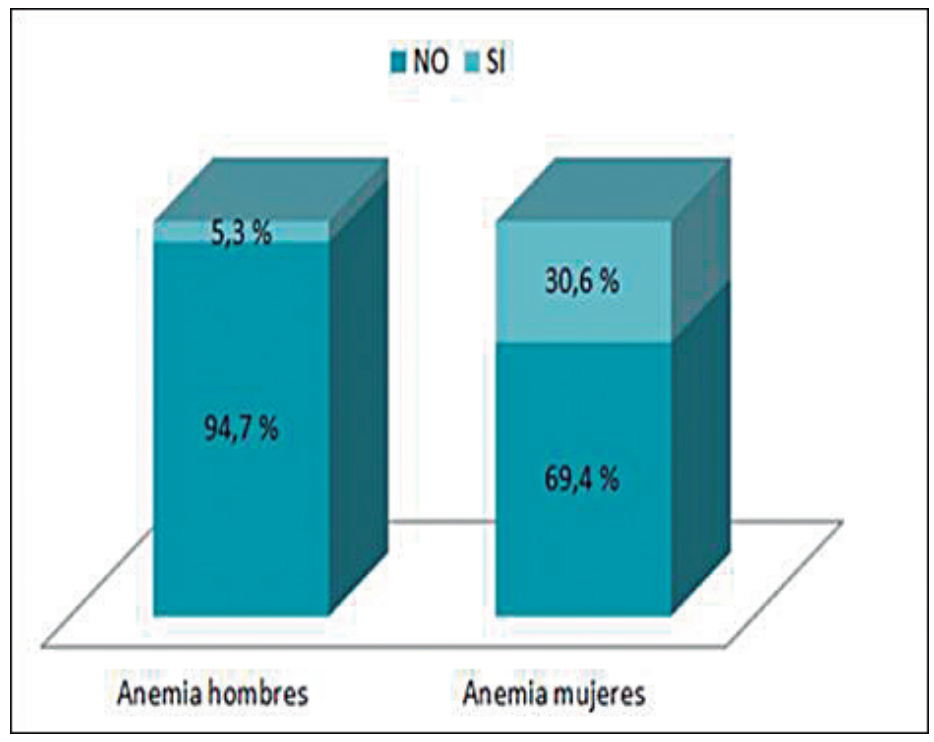

Figura 5. Presencia de anemia por género en las comunidades participantes 
Una Gran proporción de la población indígena estudiada presentó eosinofilia relativa, hallazgo encontrado en el FSP.

En un $83,9 \%$ de las personas que presenta parásitos intestinales se encontró eosinofilia, sin embargo existe una pequeña proporción de personas que no presentan parásitos intestinales y si eosinofilia, a través del test de Fisher se determinó una relación no significativa para el parasitismo intestinal y la eosinofilia de 0,45 .Tabla 1 .

Tabla 1. Relación parasitosis y eosinofilia relativa

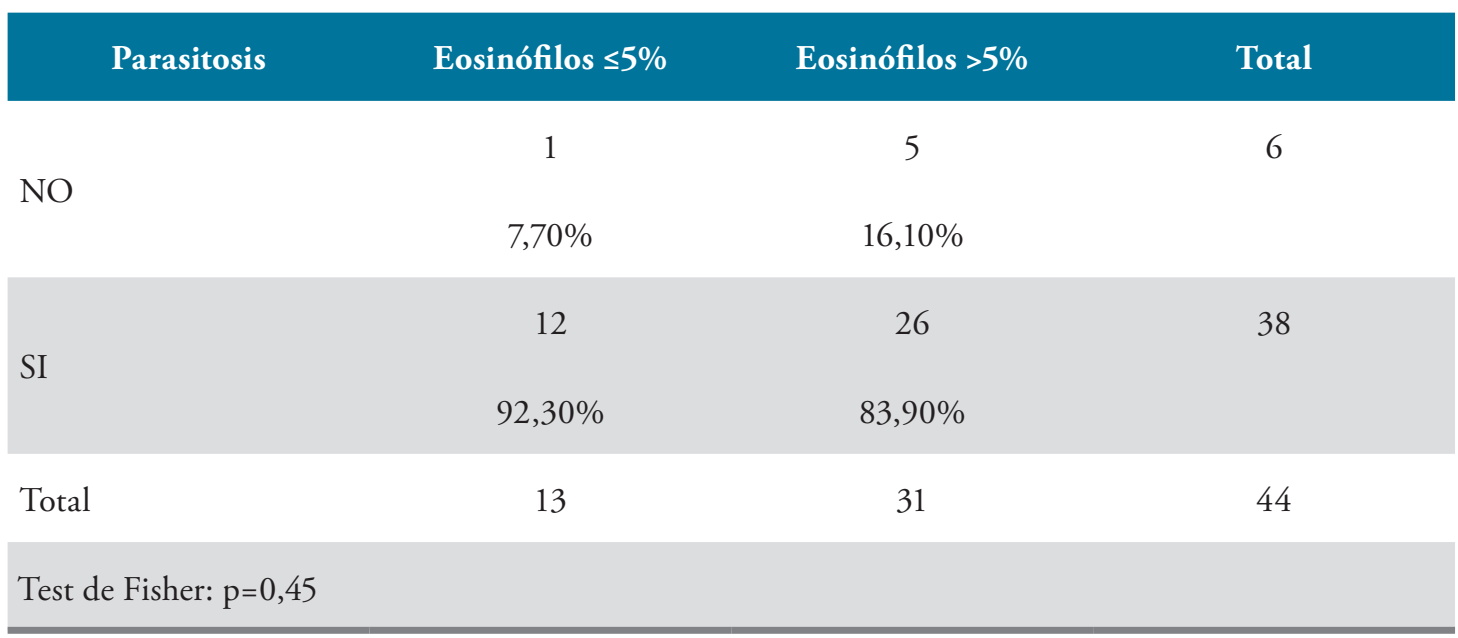

Los valores de ferritina del total de los indígenas participantes varían entre $16.1 \mathrm{ng} / \mathrm{ml}$ y 720.4 $\mathrm{ng} / \mathrm{ml}$, siendo el valor promedio de $65.92 \mathrm{ng} /$ $\mathrm{ml}$. El valor de ferritina promedio es de 76.82 $\mathrm{ng} / \mathrm{ml}$, para los hombres y de $60.17 \mathrm{ng} / \mathrm{ml}$ para las mujeres. El 7,3 \% de los hombres presentaron valores por debajo del rango normal y el 1.8 $\%$ de las mujeres presentó valores por encima del rango normal. Figura 6.

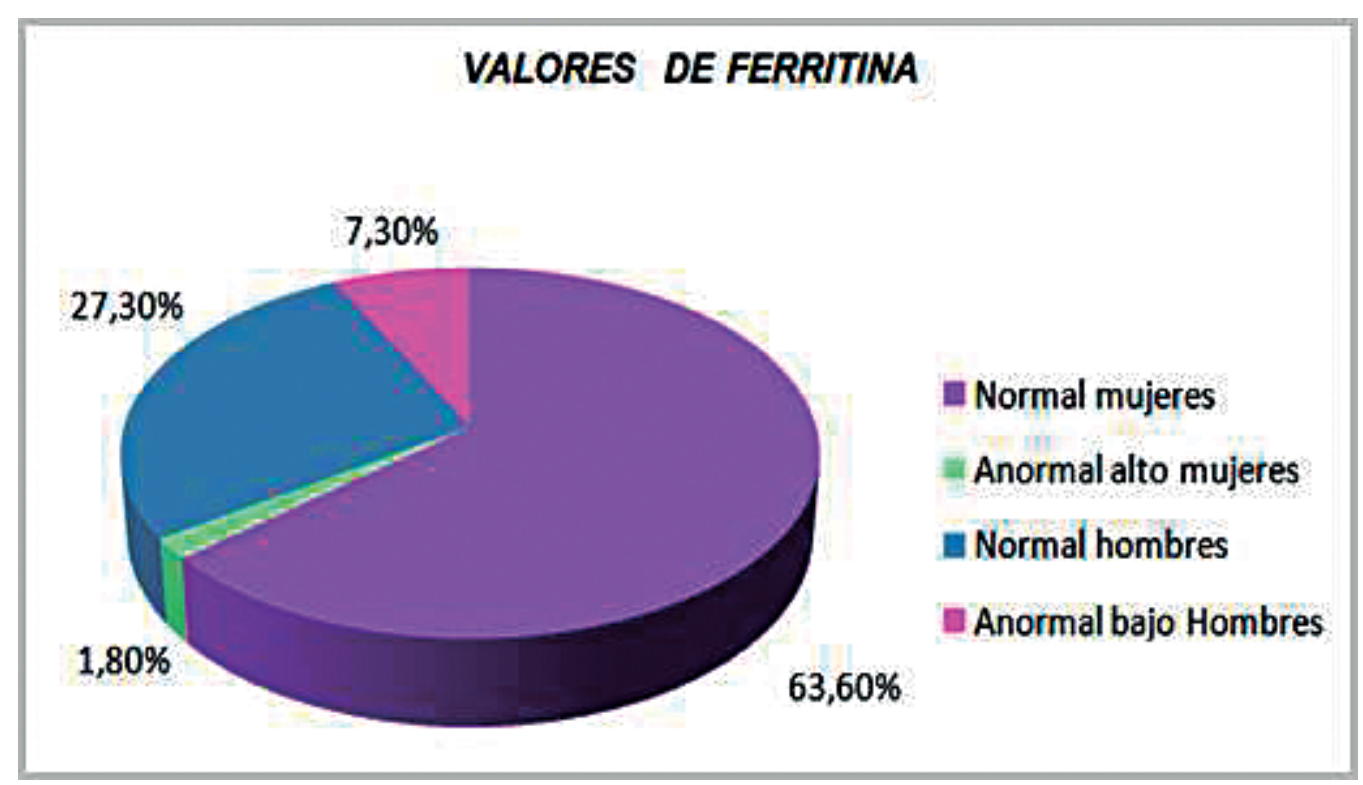

Figura 6. Determinación de los valores de ferritina en la comunidad en estudio 


\section{Discusión}

Durante el desarrollo de la investigación se encontró que varias publicaciones, entre ellas el estudio denominado "Pueblos indígenas y sistemas de información en salud: la variable étnica en 6 poblaciones Argentinas" del 2011, describen que las comunidades indígenas no cuentan con registros que se puedan analizar y permitan diseñar políticas en salud, por lo que sugiere la implementación de programas piloto en epidemiología y salud indígena (8), es por ello que este trabajo constituye un aporte hacia la construcción de estadísticas en salud a nivel del departamento de Caquetá, permitiendo la implementación de programas en salud diseñados específicamente para la población indígena y que sean realmente aplicables como lo sugiere el estudio referenciado.

En el trabajo de campo, el grupo de investigación observo que las comunidades indígenas Huitoto y Embera de Florencia, viven en la periferia de la ciudad, en zonas denominadas invasiones, no cuentan con un acueducto que les suministre agua potable, tan solo tienen conexiones de procedencia dudosa que no representan ningún tipo de seguridad sanitaria, conviven en un total hacinamiento ya que en una sola vivienda viven más de dos familias, estos aspectos conllevan a que su calidad de vida sea precaria y sus condiciones de salubridad sean deficientes.

En cuanto a la alimentación se evidencio que el consumo de carbohidratos es muy alto, el consumo de frutas y verduras es bajo, puesto que esta es la base de su agricultura, aspecto que se correlaciona con los hallazgos del estudio "Estado nutricional y hábitos alimentarios en indígenas Embera de Colombia” en el 2010 (9), estas condiciones conllevan a la presencia de obesidad o sobrepeso en algunas personas, pese a que la mayoría tiene un índice de masa corporal normal, se puede asegurar que la población no se encuentra en un estado de desnutrición sino que presenta malos hábitos alimenticios, sustentados en los factores descritos por la OMS en la publicación titulada "Dieta nutrición y prevención de enfermedades crónicas" (10).
A pesar que la mayoría cuenta con una afiliación al sistema General de seguridad social en el régimen subsidiado, otros no se encuentran afiliados, pues sus tradiciones dan mayor importancia a su medicina que a la medicina occidental. Solo existe una pequeña proporción que pertenecen al régimen contributivo ya que se encuentran trabajando en alguna empresa. Según refieren los gobernadores de los cabildos indígenas, al momento de asistir para recibir la atención médica pertinente, no son acogidos por el personal de manera cordial ni oportuna, por tal razón los indígenas prefieren no utilizar este servicio. Se evidencia que quienes viven en condiciones más vulnerables son las comunidades Embera, sin embargo tanto ellos como los Huitotos pertenecen a estratos sociales bajos.

Según el boletín epidemiológico nacional del 2009 se reporta que las comunidades indígenas han sido afectadas por enfermedades tropicales como la malaria (4). A través de la encuesta realizada, se pudo constatar que algunos integrantes de estos cabildos padecieron en algún momento de su vida paludismo o fiebre amarilla, lo anterior debido a la interacción con los vectores transmisores de estas enfermedades en zonas endémicas como lo es la ciudad de Florencia Caquetá.

La realización de las pruebas de laboratorio constituye un apoyo diagnóstico y de seguimiento para diferentes patologías, en el estudio se evidencio dentro de las dos comunidades Embera y Huitotos una prevalencia de $4 \%$ de infección urinaria detectada a través del uroanálisis.

Al comparar los resultados de la presente investigación con el estudio denominado: "Estado actual de las parasitosis intestinales en cuatro comunidades indígenas de Colombia", se observa semejanza en la presencia de parásitos intestinales como Blastocystis hominis, Endolimax nana, complejo Entamoeba histolyticaldispar y Giardia intestinalis (11), detectándose la presencia de parasitismo intestinal de $86.67 \%$ en los cuatro cabildos participantes. Es de destacar que los problemas evidenciados son consecuencia 
de la falta de conocimiento de los ciclos de vida de estos parásitos y la falta de práctica de hábitos de vida saludable.

En el análisis del cuadro hemático lo que más llama la atención es el valor de la hemoglobina que se encontró disminuida en el $5.3 \%$ de los hombres y en el $30.6 \%$ de las mujeres indígenas evidenciando estados de anemia en esta población según los valores que establece la OMS para este padecimiento. Sin embargo hay que resaltar que el valor promedio de hemoglobina para los hombres fue de $14.4 \mathrm{gr} / \mathrm{dl}$ y para las mujeres de $12.4 \mathrm{gr} / \mathrm{dl}$, lo que demuestra que la población en general se encuentra dentro de los rangos normales pero con tendencia a los límites inferiores debido a que Florencia se encuentra ubicado a $242 \mathrm{msnm}$ y sus habitantes no presentan alteraciones hematológicas fisiológicas importantes.

La determinación de ferritina en estas comunidades, indicó que cuatro hombres presentaron valores disminuidos, pero ninguno de ellos presentó anemia y en las mujeres que sí la presentaron, los valores de ferritina estuvieron dentro de los rangos normales. Lo anterior evidencia que los estados de anemia encontrados no están relacionados con deficiencia en los depósitos de hierro y que es necesario encontrar la causa de la anemia.

Es importante destacar que la disminución de ferritina en los individuos que tuvieron valores de hemoglobina dentro de los valores normales puede estar indicando disminución en las reservas de hierro y se les debe proporcionar bajo prescripción médica para evitar la aparición de anemia ferropénica.

Los resultados de proteína $\mathrm{C}$ reactiva de todos los indígenas estuvieron dentro de los valores normales, por lo tanto no se puede establecer una relación con el único valor de Ferritina que superó los valores normales y se recomienda el seguimiento de esta persona para conocer la causa del aumento tan marcado de esta proteína.
Al revisar el FSP se encontraron valores relativos de eosinófilos por encima del 5\% lo que demuestra eosinofilia en el 73\% de los indígenas participantes. A través del test de Fisher se encontró una significancia de $\mathrm{p}=0.45$ entre la parasitosis y la eosinofilia relativa que demuestra que la presencia de eosinofilia no está directamente relacionada con la presencia de parasitismo intestinal y esto se confirma ya que los parásitos encontrados no producen una respuesta inmunológica de este tipo.

\section{Referencias}

1. Organización Mundial de la Salud. La salud de los pueblos indígenas. Ginebra: OMS; 2007.

2. República de Colombia. Constitución política de Colombia Art 7. Bogotá: República de Colombia; 1991.

3. Fondo Internacional de Desarrollo Agrícola. Los pueblos indígenas: valorar, respetar y apoyar la diversidad. Roma: FIDA; 2011.

4. Instituto Nacional de Salud. Boletín Epidemiológico Nacional 2009. Bogotá: INS; 2010.

5. Núñez F, Bernal J. Estado de salud infantil en las comunidades indígenas, afrocolombianas y aisladas en Colombia. Medicina Ac. Col. 2002; 24: 27-42.

6. Diagnostic Automation, INC. Human Ferritin Enzyme Immunoassay Test Kit. USA.

7. RODELG laboratorios. REHUMA PCR. Test rápido para la determinación cualitativa y semicuantitativa de proteína $C$ por aglutinación de las partículas de látex en portaobjetos. Barranquilla, Colombia.

8. Cuyul A, Rovetto M, Specogna M. Pueblos indígenas y sistemas de información en salud: La variable étnica en seis provincias argentinas. Revista Argentina de Salud Pública [En línea], 2011 [Revisado 14 de Septiembre de 2011]; 2(7): 12-18. Disponible en: http://www.msal.gov.ar/rasp/rasp/articulos/ volumen7/art-originales pueblosindigenas.pdf

9. Rosique J, Restrepo M, Manjarrés M, Gálvez A, Santa M. Estado nutricional y hábitos alimentarios en Indígenas Embera de Colombia. Rev. chilena de nutrición [En línea], 2010 [Revisado 2 de Septiembre de 2011]; 37 (3): 270 - 280. Disponible en: http://www.scielo.cl/pdf/rchnut/v37n3/art02. pdf.

10. OMS. Dieta nutrición y prevención de enfermedades crónicas. Consulta mixta de expertos OMS/FAO. Organización mundial de la salud Ginebra. [En línea] 2003 [Revisado 8 de Junio de 2012]. Disponible en: http://whqlibdoc.who. int/trs/WHO_TRS_916_spa.pdf

11. Puerta L, Salazar L, Velásquez L, Vélez I. Estado actual de las parasitosis intestinales en cuatro comunidades indígenas de Colombia. Colombia. Revista Biomédica [En línea], 2011; [Revisado 03 de Enero de 2012]; 31(3): 98-99. Disponible en: http://revistabiomedica.org/index.php/biomedica/ article/viewFile/554/683. 